\title{
Genetic Regulation of the Host-Fungus Interaction in the Pathogenesis of Aspergillosis
}

\author{
Daniela Antunes $^{1,2} \cdot$ Cristina Cunha ${ }^{1,2} \cdot$ Agostinho Carvalho $0^{1,2}$
}

(C) Springer Science+Business Media, LLC, part of Springer Nature 2019

\begin{abstract}
Purpose of Review There is significant interindividual variability in the development and progression of fungal diseases, most notably invasive pulmonary aspergillosis (IPA). The integration of individual traits into clinically valid procedures to predict the risk and progression of infection, and the efficacy of antifungal prophylaxis and therapy, will change the current healthcare landscape regarding the management of patients at risk of IPA and, likely, other fungal infections.

Recent Findings Over the last decade, an expanding number of common polymorphisms associated with IPA have been reported, adding to the information available on monogenic defects underlying severe forms of the disease. Predisposition to IPA is therefore nowadays considered to result from a combination of clinical and host factors, with the latter being most likely regulated at the genetic level.

Summary In this review, we address the contribution of the genetic profile of the host to the outcome of the host-fungus interaction and discuss the application of this information in potential strategies with the aim of moving towards personalized prognostics, diagnostics, and treatment.
\end{abstract}

Keywords Aspergillosis - Immunocompromised host - Single nucleotide polymorphism (SNP) - Genetic susceptibility · Antifungal immunity $\cdot$ Personalized medicine

\section{Introduction}

Invasive pulmonary aspergillosis (IPA) is a life-threatening infection caused primarily by the opportunistic fungal pathogen Aspergillus fumigatus [1]. This disease commonly affects patients with impaired immune function, including those undergoing hematopoietic stem cell (HSCT) or solid organ transplantation (SOT) and cancer therapy, or with selected primary immunodeficiencies [2]. Because of the severe underlying immune dysfunctions, including neutropenia or NADPH oxidase activity, IPA is typically associated with high mortality

This article is part of the Topical Collection on Fungal Genomics and Pathogenesis

Agostinho Carvalho

agostinhocarvalho@med.uminho.pt

1 Life and Health Sciences Research Institute (ICVS), School of Medicine, University of Minho, Braga, Portugal

2 ICVS/3B's-PT Government Associate Laboratory, Braga/ Guimarães, Portugal rates. Other groups of patients with less severe or altogether lacking apparent immunosuppression are at risk of noninvasive fungal colonization. These include patients with underlying pulmonary complications, such as cystic fibrosis and chronic obstructive pulmonary disease (COPD), which are prone to develop allergic bronchopulmonary aspergillosis (ABPA) or chronic pulmonary aspergillosis (CPA), respectively [3].

The risk of fungal infection and its clinical outcome vary considerably even among patients with similar predisposing clinical conditions and microbiological exposure. Since there is currently no robust evidence for geographical or genomic factors influencing the virulence of A. fumigatus, susceptibility to infection is thought to depend mainly on genetic predisposition and the degree of pathogen exposure, with interactions between the two likely contributing substantially to the risk of infection [4-6]. Accordingly, studies in mice have revealed disparate susceptibility profiles to experimental aspergillosis between inbred strains [7], reflecting a marked contribution of heritable factors to the development of infection. Importantly, the study of individuals with rare monogenic defects and from common single nucleotide polymorphisms 
(SNPs) in cohort-based studies have pinpointed defined molecular players and mechanisms of genetic control of the antifungal immune response $[8 \bullet \bullet]$. Here, we review the relevant contribution of common human genetic variation to antifungal immunity and the mechanisms through which it predisposes to infections caused by A. fumigatus (Fig. 1).

\section{Genetic Regulation of Innate Immunity to Aspergillus}

\section{Epithelial Immunity}

The lung epithelium is the initial site of the host-fungus interaction, and recent work has underscored its critical role in defining progression from relatively innocuous colonization to overt disease [9]. Despite its importance, not much is known directly implicating epithelial immunity with the development of aspergillosis. One exception was provided recently in a study involving patients with ABPA and in which a SNP in the zinc finger protein 77 (ZNF77), whose function is required for normal epithelial integrity, was found to predispose to enhanced fungal colonization of the lungs [10॰]. Additional studies in bronchial epithelial cells whose genome was edited to harbor the risk genotype revealed a decreased epithelial integrity, with fungal conidia adhering and germinating more efficiently as the result of enhanced synthesis of adhesive extracellular proteins. Further recent studies have highlighted additional mechanisms through which epithelial immunity controls the initial stages of infection and how the fungus has instead evolved strategies to counter these mechanisms of epithelial control [11, 12]. However, it remains to be assessed whether these mechanisms of resistance are influenced by host genetic variation and how they contribute to human disease.

\section{Pattern Recognition Receptors}

Innate immune recognition of fungal cell wall components has been an area of intense research, and multiple families of pattern recognition receptors (PRRs), including C-type lectin receptors (CLRs) and Toll-like receptors (TLRs), are known to mediate the recognition of fungal cell wall components [13•]. Functionally, these PRRs induce the secretion of proinflammatory cytokines and chemokines and activate mechanisms leading to phagocytosis and production of reactive oxygen species (ROS), as well as the activation of complex immunoregulatory processes and adaptive immunity [14]. The efficiency of fungal recognition and the interaction with membrane-associated PRRs also relies largely on the opsonization by different soluble pattern recognition molecules (PRMs), including collectins, pentraxins, ficolins, and components of the complement pathway [15]. Given their pivotal role in innate antifungal immunity, it is not surprising that genetic variation in these genes constitutes major risk factors to diseases caused by a wide range of fungal pathogens [16].

\section{Toll-Like Receptors}

The TLR family is endowed with prominent genetic variability due to the strong selective pressure occurring during evolution [17]. Given the high number of polymorphic sites in the coding regions from these genes, TLRs were historically considered plausible targets for involvement in susceptibility to infectious diseases, including fungal infections [18]. The presence of a haplotype in the leucine-rich repeat region of TLR4
Fig. 1 Overview of the major innate immunity components and the cell types in which genetic defects increase susceptibility to different forms of aspergillosis. DC-SIGN, dendritic cell-specific intercellular adhesion molecule3-grabbing non-integrin; DEFB1, $\beta$-defensin 1; CARD9, caspase recruitment domain-containing protein 9; CXCL10, C-X-C motif chemokine 10; NOD2, nucleotide-binding oligomerization domaincontaining protein 2; PLG, plasminogen; PTX3, pentraxin-3; SP-A2, surfactant protein A2; TLR, Toll-like receptor; ZNF77, transcription factor zinc finger protein 77

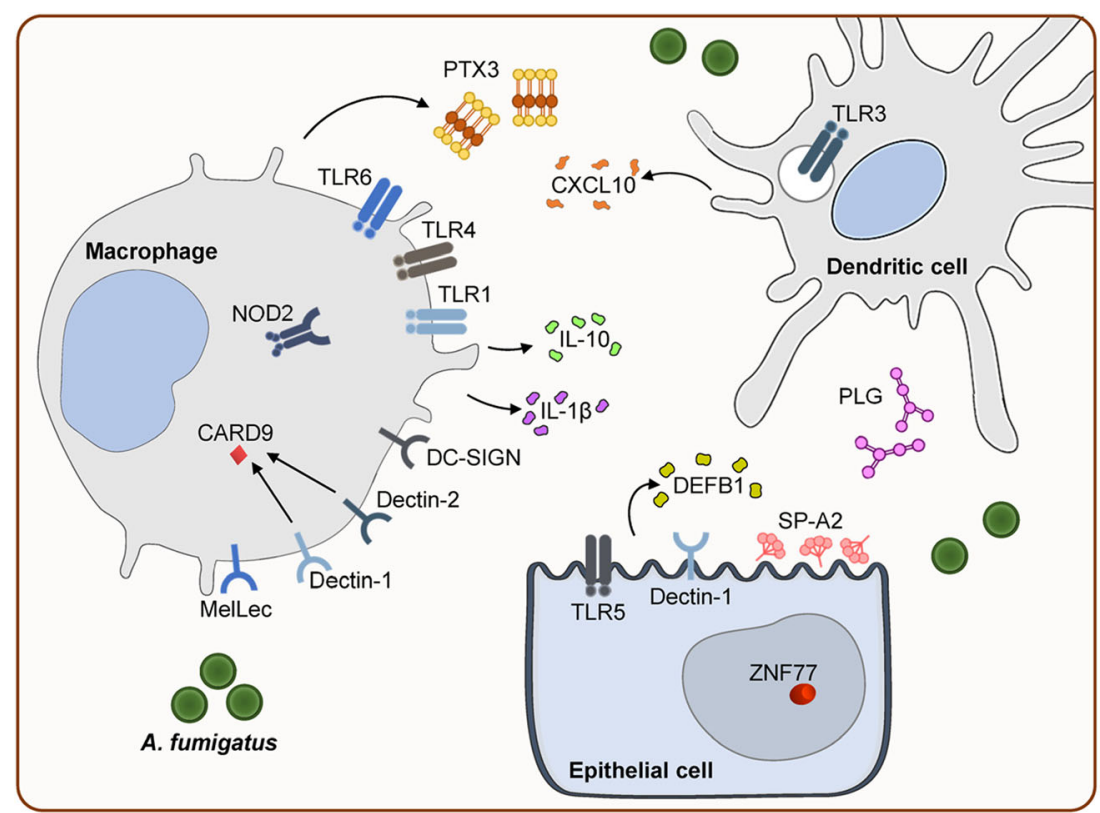


in allogeneic HSCT donors was associated with the development of IPA in the corresponding recipients [19], a finding that was validated in independent HSCT cohorts $[20,21]$ and in immunocompetent individuals suffering from CPA [22], but that failed to be replicated in other studies $[23,24 \bullet \cdot, 25]$. These discrepant findings may be related in part to the yet unknown mechanisms through which TLR4 variants may influence antifungal immune responses, particularly since no fungal ligand for TLR4 has been identified to date.

Although SNPs in additional TLRs have been reported to influence susceptibility to IPA, most of these studies involved small sample sizes and failed to provide any functional validation $[26,25]$. One relevant exception regards a study implicating a regulatory variant in TLR3 - the prototypical receptor for double-stranded RNA - in the development of IPA after HSCT [27], an association that was replicated in patients suffering from severe asthma with fungal sensitization [28]. Although definitive data demonstrating direct binding of fungal RNA to TLR3 has yet to be provided, dendritic cells from SNP carriers displayed an impaired expression of TLR3, resulting in a defective priming of memory CD8(+) T cell responses to the fungus [27]. Such functional elucidation provided pivotal evidence of how genetic defects in PRRs may influence adaptive immune responses, in addition to fungal sensing and innate immunity. Importantly, as host damage perception is also fundamental for resolution of infection, genetic variants triggering a hyperactivation of damage-associated molecular pattern signaling, and presumably leading to uncontrolled inflammatory response to the fungus, were also found to increase the risk of IPA among HSCT recipients [29].

\section{C-Type Lectin Receptors}

The CLR family includes the receptors with the most wellestablished roles in the coordination of antifungal immune responses [30]. For example, the importance of dectin-1 in the recognition of $\beta-1,3$-glucan and activation of antifungal immunity has been revealed in mouse studies and confirmed in patients with recurrent fungal infections carrying the early stop codon SNP Y238X [31, 32]. This SNP results in a truncated form of dectin-1 lacking several amino acids within the carbohydrate recognition domain, with a detrimental effect on recognition of $\beta-1,3$-glucan and cytokine production in response to fungal stimulation [33•, 31]. As a result, Y238X was also found to predispose HSCT recipients to the development of IPA in different cohorts [34, 33•]. Additional variants in dectin-1, but also dectin-2 and DC-SIGN (CD209), were likewise correlated with the development of IPA in hematological patients $[35,36]$. Importantly, dectin- 1 deficiency in both donors and recipients of HSCT was found to display a concerted action towards the risk of infection [33]. This finding was replicated in a large, independent HSCT patient cohort [24••], highlighting the key role of dectin-1 in antifungal immunity across multiple cell types. Because the spatial localization of the different dectin-1 isoforms within the cell orchestrates the signaling quality of antifungal immune responses [37, 38], it is also tempting to speculate that this may be one additional mechanism through which the Y238X variant contributes to infection.

The role of dectin-1 signaling in antifungal immunity may however extend beyond the direct activation of effector mechanisms. For example, recognition of $\beta-1,3$-glucan is nowadays acknowledged as one major mechanism involved in the establishment of innate immune memory to infection with a broad range of pathogens - a process referred to as trained immunity [39] - and that occurs through the regulation of multiple processes of cellular metabolism and epigenetic regulation [40, 41, 42••, 43]. Whether the Y238X SNP also contributes to infection by compromising the induction of "natural" trained immunity as the result of our constant exposure to fungi remains to be assessed. Either way, this may prove to be a target amenable to therapeutic manipulation, particularly in the context of fungal diseases.

In addition to dectin-1, MelLec was recently identified as another critical CLR activated in response to A. fumigatus [44••]. MelLec recognizes melanin in the cell wall of dormant conidia and is required for the induction of protective immunity to the fungus. Importantly, human monocyte-derived macrophages from carriers of a non-synonymous SNP affecting the cytoplasmic tail of MelLec, and likely impacting intracellular signal transduction, were found to display a generalized defect in the production of cytokines after fungal stimulation. As a result, HSCT patients that received transplants from donors carrying the SNP displayed a markedly increased risk of IPA after transplantation. Besides the role of melanin as a major determinant of the cell wall interaction with the innate immune system, it endows the fungus with the ability to survive killing by phagocytes, namely, by blocking phagosome biogenesis, a mechanism that depends on calcium sequestration inside the phagosome $\left[45,466^{\bullet}\right]$. Importantly, disruption of these protective mechanisms by the presence of a regulatory variant in the gene encoding calmodulin 1, likely affecting calcium signaling, increased the risk of IPA [46•]. Although the mechanisms through which MelLec and melanin orchestrate antifungal immunity are still incompletely understood [47], these findings nevertheless support the concept that CLRs are important repositories of genetic variability regulating susceptibility to IPA.

Caspase recruitment domain-containing protein 9 (CARD9) is an adaptor molecule that transduces signals from dectin- 1 and other CLRs and whose deficiency was initially identified in patients suffering from mucocutaneous fungal infections [48]. More recently however, human CARD9 deficiency was also found to predispose to extrapulmonary aspergillosis through a mechanism involving the defective accumulation of neutrophils in the infected tissue [49]. In addition to 
these rare mutations, functional studies in vivo using knock-in mice carrying the common S12N SNP have implicated common variation in CARD9 in the pathogenesis of ABPA [50]. Mechanistically, S12N contributed to the activation of NF- $\mathrm{KB}$ subunit RelB, which in turn promoted the production of IL-5 by alveolar macrophages and the recruitment of eosinophils to drive $\mathrm{Th} 2$ cell-mediated allergic responses. Given the central role of CARD9 in collecting signals from the CLR family and orchestrating signals driving antifungal immunity, it is tempting to speculate that this or other common genetic variants in CARD9 may also be relevant in patients at risk of other forms of aspergillosis and eventually other fungal infections.

\section{NOD-Like Receptors}

Besides the involvement of nucleotide-binding oligomerization domain (NOD)-like receptors (NLRs) in the formation of inflammasomes, oligomeric cytosolic structures known to play a key role in fungal sensing and immunity [51,52], the function of canonical NLRs such as NOD1 and NOD2 in host defense against fungi remained until recently poorly studied. The P268S SNP in NOD2, typically associated with inflammatory diseases, such as Crohn's disease [53], was found to confer resistance to IPA in HSCT patients [54•]. Mechanistically, mononuclear cells harboring this SNP displayed enhanced phagocytosis and killing capacity as the results of a compensatory mechanism leading to the increased expression of dectin1 , a finding that was corroborated in a mouse model of infection using NOD2-deficient mice. This variant illustrates therefore how genetic variation can influence the intricate crosstalk between innate immune receptors and highlights the possibility to disrupt NOD2 signaling as a therapeutic intervention in IPA.

\section{Pattern Recognition Molecules}

As referred above, there are several circulating molecules that are endowed with the ability to interact with and bind to microbial polysaccharides without transducing intracellular signals and that function as opsonins to facilitate recognition and phagocytosis [15]. One classical example regards the mannose-binding lectin (MBL), a CLR that binds carbohydrate patterns from microorganisms and activates the lectin pathway of the complement system [55]. There are several described combinations of nonsynonymous and promoter variants in the gene encoding MBL, either affecting the expression levels, its functional activity, or both [16]. Although there is no evidence for a contribution of genetic variants in MBL to IPA, low circulating concentrations of the protein were detected in infected patients [56]. Instead, the development of CPA was nonetheless linked with the presence of variable
MBL alleles [57, 58]. Other studies have also implicated SNPs in lung surfactant proteins, such as SP-A2, in ABPA $[59,60]$. However, most of these studies were limited by the small sample size, and these associations need to be revisited in larger and well-characterized cohorts.

Another PRM that has received a great deal of recent attention in the field of fungal diseases is the long pentraxin-3 (PTX3) [55]. This molecule binds microbial moieties from a wide range of microorganisms, including bacteria, viruses, and fungi, particularly A. fumigatus [61]. Accordingly, genetic variation in PTX3 was identified as a major risk factor for IPA after HSCT [62・•], an association that was validated in independent cohorts of recipients of HSCT [24•.0 and SOT [63, 64] and patients with COPD $[65,66]$. Mechanistically, genetic variants in PTX3 were found to compromise the normal expression of the protein in the lungs and, at a cellular level, the antifungal effector mechanisms of neutrophils were impaired [62*0]. The specific impact of PTX3 deficiency on neutrophil function was corroborated by a recent study describing the same association in patients with acute myeloid leukemia undergoing chemotherapy courses without pre-existing neutropenia [67]. Collectively, these studies support variation in PTX3 as the most robust genetic marker for IPA identified to date and lay the foundations for prospective clinical trials assessing their prognostic performance in the clinical setting.

Other mechanisms of antifungal host defense besides neutrophil function may also be regulated by PTX3 and influenced by its deficiency. For example, PTX 3 has been shown to bridge neutrophil and B cell functions in the spleen, namely, class switching, plasmablast expansion, and antibody production [68]. As such, antibodies against fungal antigens could be compromised by PTX3 deficiency, and this could represent one additional mechanism potentially explaining the association with increased susceptibility to IPA. In addition, PTX3 was found to directly bind to myeloid differentiation protein 2 (MD-2), an adapter of the TLR4 signaling complex, and this process was found to be critically required for immune protection in experimental aspergillosis [69]. This raises the possibility that the combined genetic deficiency of PTX3 and TLR4 might underlie a higher risk of IPA than the single defects alone, a hypothesis that requires further confirmation.

The clinical applicability of PTX3 in the setting of aspergillosis may also extend beyond risk stratification approaches. Levels of PTX3 in the bronchoalveolar fluids were proposed to be relatively accurate diagnostic markers for microbiologically confirmed pneumonia [70]. Because the concentrations of PTX3 in each individual are determined at the genetic level [62••], one can predict an improvement to the diagnostic performance of PTX3 by stratifying patients according to their 
genotypic profile for PTX3. In addition, PTX3 deficiency was also shown to impair the levels of alveolar cytokines, namely IL-6 and IL-8, in hematological patients suffering from IPA and to impact their ability to act as discriminators of infection [71]. Of note, because supplementing otherwise deficient neutrophils with recombinant PTX3 was sufficient to restore the efficacy of their antifungal effector functions [62・•], the targeted administration of PTX3 can be regarded as a promising prophylactic or therapeutic approach for IPA in patients at risk [72].

Plasminogen represents another example of a PRM that displays relevant genetic diversity. By performing an unbiased screen of mice subjected to experimental aspergillosis with different strains and correlating genetic data with survival, a non-synonymous variant was associated with the risk of IPA in patients undergoing HSCT [73]. These findings support the importance of additional preclinical studies testing different models of infection and evaluating additional immune-related readouts to guide the discovery of human genetic variation with an important contribution to the risk of infection.

\section{Cytokines and Chemokines}

A number of positive associations between genetic variants in cytokines (e.g., IL-1 gene cluster, IL-12, IL-10, and IFN- $\gamma$ ) and chemokines (e.g., CXCL10) and susceptibility to aspergillosis have also been reported [74-78]. One of the most relevant examples available to date regards the immunoregulatory cytokine IL-10, which has been observed at elevated levels in patients with CPA [79] and in non-neutropenic patients with IPA [80]. In addition, significant relationships between genetic variation in IL-10 and aspergillosis have been found in patients with cystic fibrosis [81], hematological patients undergoing chemotherapy [76], and HSCT recipients [82]. The latter data was recently validated in a large, twostage association study demonstrating the contribution of a specific variant in the IL-10 promoter to the risk of IPA, an association occurring, at least in part, due to a shift towards an anti-inflammatory cytokine profile in patients carrying IL-10 high-producing genotypes [83].

Other relevant reports have implicated genetic variation in IL-1 $\beta$ and beta-defensin 1 (DEFB1) in susceptibility to mold infection after SOT by affecting the production of proinflammatory cytokines by mononuclear cells [84]. In addition, a specific allele in the promoter of IFN- $\gamma$ was recently found to confer resistance to IPA [75]. Although the exact molecular mechanisms though which this variant controlled risk of infection are not known, cells harboring the implicated allele displayed nonetheless an enhanced fungicidal activity. Regarding chemokines, one robust study implicated a haplotype in CXCL10 and risk of IPA in HSCT recipients [85]. Mechanistically, this haplotype was correlated with the inability of dendritic cells to express CXCL10, and, interestingly, patients who survived IPA displayed significantly higher CXCL10 levels compared with patients without the disease. Taken together, these observations suggest the need for evaluation of interindividual variability in immune function to assess the performance of novel diagnostic and immunotherapeutic approaches for aspergillosis [86].

\section{Conclusions-Clinical Translation of Host Genetics}

Early diagnosis remains critical to obtain a favorable outcome in patients suffering from aspergillosis. However, the existing tools are often compromised by slowness, invasiveness, lack of standardization, and insufficient understanding of their kinetics [87]. Given these technical barriers, the search for diagnostic tools that are more efficient and reliable is an active field of research. Although the interaction of the fungus with the immune system is being exploited to project novel and improved fungal diagnostics, efforts have on the other hand been also devoted to the implementation of clinical models aimed at the prediction of infection in high-risk patients. In this regard, interpretation of individual signatures associated with impaired antifungal immune responses and their integration with clinical data is regarded as a promising approach [88]. However, because the effect size of single variants may not be discriminatory enough to support clinical decisions, there is the need to account for a broader set of variants, likely impacting different, yet equally relevant, susceptibility mechanisms [6]. As a matter of fact, a recent study evaluating the combination of multiple genetic and clinical factors into a predictive model has demonstrated that such information could be used to successfully guide preemptive therapy in hematological patients [89].

Besides improved diagnostics, functional analyses of genetic variation known to impact susceptibility to infection remain a priority, since an improved understanding of the multiple targets and pathways affected by genetic variation may contribute to the establishment of innovative and personalized immunotherapeutics. This is illustrated by the pre-clinical evidence showing that genetic PTX3 deficiency can be rescued by the exogenous administration of the protein, a finding that may support its personalized use in specific patients at high risk of infection. In conclusion, the success of novel diagnostic and immunotherapeutic approaches for IPA and likely other fungal diseases will only be possible if guided by personalization based on the interindividual variability in antifungal immune function. 


\section{Compliance with Ethical Standards}

Conflict of Interest Agostinho Carvalho reports that the work was supported by the Northern Portugal Regional Operational Programme (NORTE 2020), under the Portugal 2020 Partnership Agreement, through the European Regional Development Fund (FEDER) (NORTE-01-0145FEDER-000013); the Fundação para a Ciência e Tecnologia (FCT) (IF/ 00735/2014 and CEECIND/03628/2017); and the European Society of Clinical Microbiology and Infectious Diseases (ESCMID Research Grant 2017). Cristina Cunha reports funding from the Fundação para a Ciência e Tecnologia (FCT) (PTDC/SAU-SER/29635/2017 and CEECIND/04601/ 2017) and the Institut Mérieux (Mérieux Research Grant 2017).

Daniela Antunes declares no conflicts of interest relevant to this manuscript.

Human and Animal Rights and Informed Consent This article does not contain any studies with human or animal subjects performed by any of the authors.

\section{References}

Papers of particular interest, published recently, have been highlighted as:

- Of importance

•- Of major importance

1. Segal BH. Aspergillosis. N Engl J Med. 2009;360(18):1870-84. https://doi.org/10.1056/NEJMra0808853.

2. Brown GD, Denning DW, Gow NA, Levitz SM, Netea MG, White TC. Hidden killers: human fungal infections. Sci Transl Med. 2012;4(165):165rv113. https://doi.org/10.1126/scitranslmed. 3004404.

3. Kosmidis C, Denning DW. The clinical spectrum of pulmonary aspergillosis. Thorax. 2015;70(3):270-7. https://doi.org/10.1136/ thoraxjnl-2014-206291.

4. Campos CF, van de Veerdonk FL, Goncalves SM, Cunha C, Netea MG, Carvalho A. Host genetic signatures of susceptibility to fungal disease. Curr Top Microbiol Immunol. 2018. https://doi.org/10. 1007/82_2018_113.

5. Cunha C, Aversa F, Romani L, Carvalho A. Human genetic susceptibility to invasive aspergillosis. PLoS Pathog. 2013;9(8): e1003434. https://doi.org/10.1371/journal.ppat.1003434.

6. Cunha $\mathrm{C}$, Carvalho A. Genetic defects in fungal recognition and susceptibility to invasive pulmonary aspergillosis. Med Mycol. 2019;57(Supplement_2):S211-8. https://doi.org/10.1093/mmy/ myy057.

7. Durrant C, Tayem H, Yalcin B, Cleak J, Goodstadt L, de Villena FP, et al. Collaborative Cross mice and their power to map host susceptibility to Aspergillus fumigatus infection. Genome Res. 2011;21(8):1239-48. https://doi.org/10.1101/gr.118786.110.

8.• Lionakis MS, Levitz SM. Host control of fungal infections: lessons from basic studies and human cohorts. Annu Rev Immunol. 2018;36:157-91. https://doi.org/10.1146/annurev-immunol042617-053318 Excellent review on the factors underlying susceptibility to fungal disease in the context of both primary and acquired immunodeficiencies.

9. Bertuzzi M, Hayes GE, Icheoku UJ, van Rhijn N, Denning DW, Osherov N, et al. Anti-Aspergillus activities of the respiratory epithelium in health and disease. J Fungi (Basel). 2018;4(1):E8.

10. Gago S, Overton NLD, Ben-Ghazzi N, Novak-Frazer L, Read ND, Denning DW, et al. Lung colonization by Aspergillus fumigatus is controlled by ZNF77. Nat Commun. 2018;9(1):3835. https://doi. org/10.1038/s41467-018-06148-7 A study describing genetic variation in the ZNF77 transcription factor as a risk factor for ABPA as the result of compromised integrity and function of the bronchial epithelium.

11. Liu H, Lee MJ, Solis NV, Phan QT, Swidergall M, Ralph B, et al. Aspergillus fumigatus CalA binds to integrin alpha5beta1 and mediates host cell invasion. Nat Microbiol. 2016;2:16211. https://doi. org/10.1038/nmicrobiol.2016.211.

12. Richard N, Marti L, Varrot A, Guillot L, Guitard J, Hennequin C, et al. Human bronchial epithelial cells inhibit Aspergillus fumigatus germination of extracellular conidia via FleA recognition. Sci Rep. 2018;8(1):15699. https://doi.org/10.1038/s41598-018-33902-0.

13. van de Veerdonk FL, Gresnigt MS, Romani L, Netea MG, Latge JP. Aspergillus fumigatus morphology and dynamic host interactions. Nat Rev Microbiol. 2017;15(11):661-74. https://doi.org/10.1038/ nrmicro.2017.90 Extensive review on the fungal and host factors that regulate the outcome of infections by $A$. fumigatus.

14. Patin EC, Thompson A, Orr SJ. Pattern recognition receptors in fungal immunity. Semin Cell Dev Biol. 2018;89:24-33. https:// doi.org/10.1016/j.semcdb.2018.03.003.

15. Bidula S, Schelenz S. A sweet response to a sour situation: the role of soluble pattern recognition receptors in the innate immune response to invasive Aspergillus fumigatus infections. PLoS Pathog. 2016;12(7):e1005637. https://doi.org/10.1371/journal.ppat. 1005637.

16. Carvalho A, Cunha C, Pasqualotto AC, Pitzurra L, Denning DW, Romani L. Genetic variability of innate immunity impacts human susceptibility to fungal diseases. Int J Infect Dis. 2010;14(6):e460 8. https://doi.org/10.1016/j.ijid.2009.06.028.

17. Quach H, Wilson D, Laval G, Patin E, Manry J, Guibert J, et al. Different selective pressures shape the evolution of Toll-like receptors in human and African great ape populations. Hum Mol Genet. 2013;22(23):4829-40. https://doi.org/10.1093/hmg/ddt335.

18. Cunha C, Romani L, Carvalho A. Cracking the Toll-like receptor code in fungal infections. Expert Rev Anti-Infect Ther. 2010;8(10): 1121-37. https://doi.org/10.1586/eri.10.93.

19. Bochud PY, Chien JW, Marr KA, Leisenring WM, Upton A, Janer $\mathrm{M}$, et al. Toll-like receptor 4 polymorphisms and aspergillosis in stem-cell transplantation. N Engl J Med. 2008;359(17):1766-77. https://doi.org/10.1056/NEJMoa0802629.

20. de Boer MG, Jolink H, Halkes CJ, van der Heiden PL, Kremer D, Falkenburg JH, et al. Influence of polymorphisms in innate immunity genes on susceptibility to invasive aspergillosis after stem cell transplantation. PLoS One. 2011;6(4):e18403. https://doi.org/10. 1371/journal.pone.0018403.

21. Koldehoff M, Beelen DW, Elmaagacli AH. Increased susceptibility for aspergillosis and post-transplant immune deficiency in patients with gene variants of TLR4 after stem cell transplantation. Transpl Infect Dis. 2013;15(5):533-9. https://doi.org/10.1111/tid.12115.

22. Carvalho A, Pasqualotto AC, Pitzurra L, Romani L, Denning DW, Rodrigues F. Polymorphisms in toll-like receptor genes and susceptibility to pulmonary aspergillosis. J Infect Dis. 2008;197(4):61821. https://doi.org/10.1086/526500.

23. Carvalho A, Cunha C, Carotti A, Aloisi T, Guarrera O, Di Ianni M, et al. Polymorphisms in Toll-like receptor genes and susceptibility to infections in allogeneic stem cell transplantation. Exp Hematol. 2009;37(9):1022-9. https://doi.org/10.1016/j.exphem.2009.06. 004.

24.• Fisher CE, Hohl TM, Fan W, Storer BE, Levine DM, Zhao LP, et al. Validation of single nucleotide polymorphisms in invasive aspergillosis following hematopoietic cell transplantation. Blood. 2017;129(19):2693-701. https://doi.org/10.1182/blood-2016-10743294 A large-scale study that validated the association of genetic variants in PTX3 and dectin-1 with the risk of aspergillosis after stem cell transplantation. 
25. Kesh S, Mensah NY, Peterlongo P, Jaffe D, Hsu K, M VDB, et al. TLR1 and TLR6 polymorphisms are associated with susceptibility to invasive aspergillosis after allogeneic stem cell transplantation. Ann N Y Acad Sci. 2005;1062:95-103. https://doi.org/10.1196/ annals.1358.012.

26. Grube M, Loeffler J, Mezger M, Kruger B, Echtenacher B, Hoffmann P, et al. TLR5 stop codon polymorphism is associated with invasive aspergillosis after allogeneic stem cell transplantation. Med Mycol. 2013;51(8):818-25. https://doi.org/10.3109/ 13693786.2013 .809630$.

27. Carvalho A, De Luca A, Bozza S, Cunha C, D'Angelo C, Moretti S, et al. TLR3 essentially promotes protective class I-restricted memory CD8(+) T-cell responses to Aspergillus fumigatus in hematopoietic transplanted patients. Blood. 2012;119(4):967-77. https:// doi.org/10.1182/blood-2011-06-362582.

28. Overton NL, Simpson A, Bowyer P, Denning DW. Genetic susceptibility to severe asthma with fungal sensitization. Int $\mathrm{J}$ Immunogenet. 2017;44(3):93-106. https://doi.org/10.1111/iji. 12312.

29. Cunha C, Giovannini G, Pierini A, Bell AS, Sorci G, Riuzzi F, et al. Genetically-determined hyperfunction of the S100B/RAGE axis is a risk factor for aspergillosis in stem cell transplant recipients. PLoS One. 2011;6(11):e27962. https://doi.org/10.1371/journal.pone. 0027962 .

30. Brown GD, Willment JA, Whitehead L. C-type lectins in immunity and homeostasis. Nat Rev Immunol. 2018;18:374-89. https://doi. org/10.1038/s41577-018-0004-8.

31. Ferwerda B, Ferwerda G, Plantinga TS, Willment JA, van Spriel $\mathrm{AB}$, Venselaar H, et al. Human dectin-1 deficiency and mucocutaneous fungal infections. N Engl J Med. 2009;361(18):1760-7. https://doi.org/10.1056/NEJMoa0901053.

32. Taylor PR, Tsoni SV, Willment JA, Dennehy KM, Rosas M, Findon $\mathrm{H}$, et al. Dectin-1 is required for beta-glucan recognition and control of fungal infection. Nat Immunol. 2007;8(1):31-8. https://doi.org/ 10.1038/ni1408

33. Cunha C, Di Ianni M, Bozza S, Giovannini G, Zagarella S, Zelante T, et al. Dectin-1 Y238X polymorphism associates with susceptibility to invasive aspergillosis in hematopoietic transplantation through impairment of both recipient- and donor-dependent mechanisms of antifungal immunity. Blood. 2010;116(24):5394-402. https://doi.org/10.1182/blood-2010-04-279307 The first report describing the requisite role of dectin-1 and the impact of its deficiency in both hematopoietic and non-hematopoietic compartments to antifungal immunity.

34. Chai LY, de Boer MG, van der Velden WJ, Plantinga TS, van Spriel $\mathrm{AB}$, Jacobs $\mathrm{C}$, et al. The Y238X stop codon polymorphism in the human beta-glucan receptor dectin-1 and susceptibility to invasive aspergillosis. J Infect Dis. 2011;203(5):736-43. https://doi.org/10. 1093/infdis/jiq102.

35. Fischer M, Spies-Weisshart B, Schrenk K, Gruhn B, Wittig S, Glaser A, et al. Polymorphisms of dectin-1 and TLR2 predispose to invasive fungal disease in patients with acute myeloid leukemia. PLoS One. 2016;11(3):e0150632. https://doi.org/10.1371/journal. pone. 0150632 .

36. Sainz J, Lupianez CB, Segura-Catena J, Vazquez L, Rios R, Oyonarte S, et al. Dectin-1 and DC-SIGN polymorphisms associated with invasive pulmonary aspergillosis infection. PLoS One. 2012;7(2):e32273. https://doi.org/10.1371/journal.pone.0032273.

37. Carvalho A, Giovannini G, De Luca A, D'Angelo C, Casagrande A, Iannitti RG, et al. Dectin-1 isoforms contribute to distinct Th1/ Th17 cell activation in mucosal candidiasis. Cell Mol Immunol. 2012;9(3):276-86. https://doi.org/10.1038/cmi.2012.1.

38. Fischer M, Muller JP, Spies-Weisshart B, Grafe C, Kurzai O, Hunniger K, et al. Isoform localization of dectin-1 regulates the signaling quality of anti-fungal immunity. Eur J Immunol. 2017;47(5):848-59. https://doi.org/10.1002/eji.201646849.
39. Netea MG, van der Meer JW. Trained immunity: an ancient way of remembering. Cell Host Microbe. 2017;21(3):297-300. https://doi. org/10.1016/j.chom.2017.02.003.

40. Arts RJ, Novakovic B, Ter Horst R, Carvalho A, Bekkering S, Lachmandas E, et al. Glutaminolysis and fumarate accumulation integrate immunometabolic and epigenetic programs in trained immunity. Cell Metab. 2016;24(6):807-19. https://doi.org/10.1016/j. cmet.2016.10.008.

41. Bekkering S, Arts RJW, Novakovic B, Kourtzelis I, van der Heijden $\mathrm{C}$, Li Y, et al. Metabolic induction of trained immunity through the mevalonate pathway. Cell. 2018;172(1-2):135-46 e139. https:// doi.org/10.1016/j.cell.2017.11.025.

42.• Cheng SC, Quintin J, Cramer RA, Shepardson KM, Saeed S, Kumar V, et al. mTOR- and HIF-1alpha-mediated aerobic glycolysis as metabolic basis for trained immunity. Science. 2014;345(6204):1250684. https://doi.org/10.1126/science. 1250684 The first demonstration that induction of innate immune memory-trained immunity-requires the metabolic reprogramming of immune cells.

43. Dominguez-Andres J, Novakovic B, Li Y, Scicluna BP, Gresnigt MS, Arts RJW, et al. The itaconate pathway is a central regulatory node linking innate immune tolerance and trained immunity. Cell Metab. 2018;29:211-220.e5. https://doi.org/10.1016/j.cmet.2018. 09.003 .

44.• Stappers MHT, Clark AE, Aimanianda V, Bidula S, Reid DM, Asamaphan P, et al. Recognition of DHN-melanin by a C-type lectin receptor is required for immunity to Aspergillus. Nature. 2018;555(7696):382-6. https://doi.org/10.1038/nature25974 A study that identified MelLec as a novel receptor for DHNmelanin from A. fumigatus and that characterized genetic variation in MelLec as a key risk factor for aspergillosis.

45. Akoumianaki T, Kyrmizi I, Valsecchi I, Gresnigt MS, Samonis G, Drakos E, et al. Aspergillus cell wall melanin blocks LC3associated phagocytosis to promote pathogenicity. Cell Host Microbe. 2016;19(1):79-90. https://doi.org/10.1016/j.chom.2015. 12.002.

46. Kyrmizi I, Ferreira H, Carvalho A, Figueroa JAL, Zarmpas P, Cunha $\mathrm{C}$, et al. Calcium sequestration by fungal melanin inhibits calcium-calmodulin signalling to prevent LC3-associated phagocytosis. Nat Microbiol. 2018;3(7):791-803. https://doi.org/10.1038/ $\mathrm{s} 41564-018-0167-\mathrm{x}$ A study that revealed calcium signaling as a major molecular mechanism activating LC3-associated phagocytosis and fungal clearance by immune cells.

47. Casadevall A. Melanin triggers antifungal defences. Nature. 2018;555(7696):319-20. https://doi.org/10.1038/d41586-01802370-x.

48. Glocker EO, Hennigs A, Nabavi M, Schaffer AA, Woellner C, Salzer U, et al. A homozygous CARD9 mutation in a family with susceptibility to fungal infections. N Engl J Med. 2009;361(18): 1727-35. https://doi.org/10.1056/NEJMoa0810719.

49. Rieber N, Gazendam RP, Freeman AF, Hsu AP, Collar AL, Sugui JA, et al. Extrapulmonary Aspergillus infection in patients with CARD9 deficiency. JCI Insight. 2016;1(17):e89890. https://doi. org/10.1172/jci.insight. 89890.

50. Xu X, Xu JF, Zheng G, Lu HW, Duan JL, Rui W, et al. CARD9(S12N) facilitates the production of IL-5 by alveolar macrophages for the induction of type 2 immune responses. Nat Immunol. 2018;19:547-60. https://doi.org/10.1038/s41590-018 0112-4.

51. Briard B, Karki R, Malireddi RKS, Bhattacharya A, Place DE, Mavuluri J, et al. Fungal ligands released by innate immune effectors promote inflammasome activation during Aspergillus fumigatus infection. Nat Microbiol. 2018;4:316-27. https://doi. org/10.1038/s41564-018-0298-0.

52. Karki R, Man SM, Malireddi RK, Gurung P, Vogel P, Lamkanfi M, et al. Concerted activation of the AIM2 and NLRP3 
inflammasomes orchestrates host protection against Aspergillus infection. Cell Host Microbe. 2015;17(3):357-68. https://doi.org/10. 1016/j.chom.2015.01.006

53. Caruso R, Warner N, Inohara N, Nunez G. NOD1 and NOD2: signaling, host defense, and inflammatory disease. Immunity. 2014;41(6):898-908. https://doi.org/10.1016/j.immuni.2014.12. 010.

54. Gresnigt MS, Cunha C, Jaeger M, Gonçalves SM, Subbarao Malireddi RK, Ammerdorfer A, et al. Genetic deficiency of NOD2 confers resistance to invasive aspergillosis. Nat Commun. 2018;9:2636. https://doi.org/10.1038/s41467-018-04912-3 A study illustrating the involvement of NOD2 and its genetic variation in antifungal immunity and the development of aspergillosis.

55. Foo SS, Reading PC, Jaillon S, Mantovani A, Mahalingam S. Pentraxins and collectins: friend or foe during pathogen invasion? Trends Microbiol. 2015;23(12):799-811. https://doi.org/10.1016/j. tim.2015.09.006.

56. Lambourne J, Agranoff D, Herbrecht R, Troke PF, Buchbinder A, Willis F, et al. Association of mannose-binding lectin deficiency with acute invasive aspergillosis in immunocompromised patients. Clin Infect Dis. 2009;49(10):1486-91. https://doi.org/10.1086/ 644619.

57. Crosdale DJ, Poulton KV, Ollier WE, Thomson W, Denning DW. Mannose-binding lectin gene polymorphisms as a susceptibility factor for chronic necrotizing pulmonary aspergillosis. J Infect Dis. 2001;184(5):653-6. https://doi.org/10.1086/322791.

58. Vaid M, Kaur S, Sambatakou H, Madan T, Denning DW, Sarma PU. Distinct alleles of mannose-binding lectin (MBL) and surfactant proteins A (SP-A) in patients with chronic cavitary pulmonary aspergillosis and allergic bronchopulmonary aspergillosis. Clin Chem Lab Med. 2007;45(2):183-6. https://doi.org/10.1515/ CCLM.2007.033.

59. Saxena S, Madan T, Shah A, Muralidhar K, Sarma PU. Association of polymorphisms in the collagen region of SP-A2 with increased levels of total IgE antibodies and eosinophilia in patients with allergic bronchopulmonary aspergillosis. J Allergy Clin Immunol. 2003;111(5):1001-7.

60. Madan T, Eggleton P, Kishore U, Strong P, Aggrawal SS, Sarma $\mathrm{PU}$, et al. Binding of pulmonary surfactant proteins A and D to Aspergillus fumigatus conidia enhances phagocytosis and killing by human neutrophils and alveolar macrophages. Infect Immun. 1997;65(8):3171-9.

61. Garlanda C, Hirsch E, Bozza S, Salustri A, De Acetis M, Nota R, et al. Non-redundant role of the long pentraxin PTX3 in anti-fungal innate immune response. Nature. 2002;420(6912):182-6. https:// doi.org/10.1038/nature01195.

62.• Cunha C, Aversa F, Lacerda JF, Busca A, Kurzai O, Grube M, et al. Genetic PTX3 deficiency and aspergillosis in stem-cell transplantation. N Engl J Med. 2014;370(5):421-32. https://doi.org/10.1056/ NEJMoa1211161 A study demonstrating the pivotal contribution of genetic variation in PTX3 to aspergillosis as the result of impaired antifungal effector functions of neutrophils.

63. Cunha C, Monteiro AA, Oliveira-Coelho A, Kuhne J, Rodrigues F, Sasaki SD, et al. PTX3-based genetic testing for risk of aspergillosis after lung transplant. Clin Infect Dis. 2015;61(12):1893-4. https:// doi.org/10.1093/cid/civ679.

64. Wojtowicz A, Lecompte TD, Bibert S, Manuel O, Rueger S, Berger $\mathrm{C}$, et al. PTX3 polymorphisms and invasive mold infections after solid organ transplant. Clin Infect Dis. 2015;61(4):619-22. https:// doi.org/10.1093/cid/civ386.

65. Cunha $\mathrm{C}$, Carvalho A. Toward the identification of a genetic risk signature for pulmonary aspergillosis in chronic obstructive pulmonary disease. Clin Infect Dis. 2018;66(7):1153-4. https://doi.org/ $10.1093 / \mathrm{cid} / \mathrm{cix} 944$
66. He Q, Li H, Rui Y, Liu L, He B, Shi Y, et al. Pentraxin 3 gene polymorphisms and pulmonary aspergillosis in chronic obstructive pulmonary disease patients. Clin Infect Dis. 2018;66(2):261-7. https://doi.org/10.1093/cid/cix749.

67. Brunel AS, Wojtowicz A, Lamoth F, Spertini O, Neofytos D, Calandra T, et al. Pentraxin-3 polymorphisms and invasive mold infections in acute leukemia patients receiving intensive chemotherapy. Haematologica. 2018;103(11):e527-30. https://doi.org/10. 3324/haematol.2018.195453.

68. Chorny A, Casas-Recasens S, Sintes J, Shan M, Polentarutti N, Garcia-Escudero R, et al. The soluble pattern recognition receptor PTX3 links humoral innate and adaptive immune responses by helping marginal zone B cells. J Exp Med. 2016;213(10):216785. https://doi.org/10.1084/jem.20150282.

69. Bozza S, Campo S, Arseni B, Inforzato A, Ragnar L, Bottazzi B, et al. PTX3 binds MD-2 and promotes TRIF-dependent immune protection in aspergillosis. J Immunol. 2014;193(5):2340-8. https:// doi.org/10.4049/jimmunol.1400814.

70. Mauri T, Coppadoro A, Bombino M, Bellani G, Zambelli V, Fornari $\mathrm{C}$, et al. Alveolar pentraxin 3 as an early marker of microbiologically confirmed pneumonia: a threshold-finding prospective observational study. Crit Care. 2014;18(5):562. https://doi.org/10.1186/ s13054-014-0562-5.

71. Gonçalves SM, Lagrou K, Rodrigues CS, Campos CF, BernalMartínez L, Rodrigues F, et al. Evaluation of bronchoalveolar lavage fluid cytokines as biomarkers for invasive pulmonary aspergillosis in at-risk patients. Front Microbiol. 2017;8:2362. https:// doi.org/10.3389/fmicb.2017.02362.

72. Carvalho A, Cunha C, Bistoni F, Romani L. Immunotherapy of aspergillosis. Clin Microbiol Infect. 2012;18(2):120-5. https://doi. org/10.1111/j.1469-0691.2011.03681.x.

73. Zaas AK, Liao G, Chien JW, Weinberg C, Shore D, Giles SS, et al. Plasminogen alleles influence susceptibility to invasive aspergillosis. PLoS Genet. 2008;4(6):e1000101. https://doi.org/10.1371/ journal.pgen. 1000101 .

74. Carvalho A, Cunha C, Di Ianni M, Pitzurra L, Aloisi T, Falzetti F, et al. Prognostic significance of genetic variants in the IL-23/Th17 pathway for the outcome of T cell-depleted allogeneic stem cell transplantation. Bone Marrow Transplant. 2010;45(11):1645-52. https://doi.org/10.1038/bmt.2010.28.

75. Lupianez CB, Canet LM, Carvalho A, Alcazar-Fuoli L, Springer J, Lackner M, et al. Polymorphisms in host immunity-modulating genes and risk of invasive aspergillosis: results from the AspBIOmics consortium. Infect Immun. 2015;84(3):643-57. https://doi.org/10.1128/IAI.01359-15.

76. Sainz J, Hassan L, Perez E, Romero A, Moratalla A, LopezFernandez E, et al. Interleukin-10 promoter polymorphism as risk factor to develop invasive pulmonary aspergillosis. Immunol Lett. 2007;109(1):76-82. https://doi.org/10.1016/j.imlet.2007.01.005.

77. Sainz J, Perez E, Gomez-Lopera S, Jurado M. IL1 gene cluster polymorphisms and its haplotypes may predict the risk to develop invasive pulmonary aspergillosis and modulate $\mathrm{C}$-reactive protein level. J Clin Immunol. 2008;28(5):473-85. https://doi.org/10.1007/ s10875-008-9197-0.

78. Sainz J, Perez E, Hassan L, Moratalla A, Romero A, Collado MD, et al. Variable number of tandem repeats of TNF receptor type 2 promoter as genetic biomarker of susceptibility to develop invasive pulmonary aspergillosis. Hum Immunol. 2007;68(1):41-50. https:// doi.org/10.1016/j.humimm.2006.10.011.

79. Rodland EK, Ueland T, Bjornsen S, Sagen EL, Dahl CP, Naalsund $\mathrm{A}$, et al. Systemic biomarkers of inflammation and haemostasis in patients with chronic necrotizing pulmonary aspergillosis. BMC Infect Dis. 2012;12:144. https://doi.org/10.1186/1471-2334-12144.

80. Roilides E, Sein T, Roden M, Schaufele RL, Walsh TJ. Elevated serum concentrations of interleukin-10 in nonneutropenic patients 
with invasive aspergillosis. J Infect Dis. 2001;183(3):518-20. https://doi.org/10.1086/318077.

81. Brouard J, Knauer N, Boelle PY, Corvol H, Henrion-Caude A, Flamant $\mathrm{C}$, et al. Influence of interleukin-10 on Aspergillus fumigatus infection in patients with cystic fibrosis. J Infect Dis. 2005;191(11):1988-91. https://doi.org/10.1086/429964.

82. Seo KW, Kim DH, Sohn SK, Lee NY, Chang HH, Kim SW, et al. Protective role of interleukin-10 promoter gene polymorphism in the pathogenesis of invasive pulmonary aspergillosis after allogeneic stem cell transplantation. Bone Marrow Transplant. 2005;36(12):1089-95. https://doi.org/10.1038/sj.bmt.1705181.

83. Cunha C, Goncalves SM, Duarte-Oliveira C, Leite L, Lagrou K, Marques A, et al. IL-10 overexpression predisposes to invasive aspergillosis by suppressing antifungal immunity. J Allergy Clin Immunol. 2017;140(3):867-70 e869. https://doi.org/10.1016/j. jaci.2017.02.034.

84. Wojtowicz A, Gresnigt MS, Lecompte T, Bibert S, Manuel O, Joosten LA, et al. IL1B and DEFB1 polymorphisms increase susceptibility to invasive mold infection after solid-organ transplantation. J Infect Dis. 2015;211(10):1646-57.

85. Mezger M, Steffens M, Beyer M, Manger C, Eberle J, Toliat MR, et al. Polymorphisms in the chemokine (C-X-C motif) ligand 10 are associated with invasive aspergillosis after allogeneic stem-cell transplantation and influence CXCL10 expression in monocyte- derived dendritic cells. Blood. 2008;111(2):534-6. https://doi.org/ 10.1182/blood-2007-05-090928.

86. Armstrong-James D, Brown GD, Netea MG, Zelante T, Gresnigt MS, van de Veerdonk FL, et al. Immunotherapeutic approaches to treatment of fungal diseases. Lancet Infect Dis. 2017;17(12):e393402. https://doi.org/10.1016/S1473-3099(17)30442-5.

87. Hope WW, Walsh TJ, Denning DW. Laboratory diagnosis of invasive aspergillosis. Lancet Infect Dis. 2005;5(10):609-22. https:// doi.org/10.1016/S1473-3099(05)70238-3.

88. Oliveira-Coelho A, Rodrigues F, Campos A Jr, Lacerda JF, Carvalho A, Cunha C. Paving the way for predictive diagnostics and personalized treatment of invasive aspergillosis. Front Microbiol. 2015;6:411. https://doi.org/10.3389/fmicb.2015.00411.

89. White PL, Parr C, Barnes RA. Predicting invasive aspergillosis in hematology patients by combining clinical and genetic risk factors with early diagnostic biomarkers. J Clin Microbiol. 2018;56(1). https://doi.org/10.1128/JCM.01122-17.

Publisher's Note Springer Nature remains neutral with regard to jurisdictional claims in published maps and institutional affiliations. 